\title{
Effect of anthropogenic aerosol emissions on precipitation in warm conveyor belts in the western North Pacific in winter - a model study with ECHAM6-HAM
}

\author{
Hanna Joos $^{1}$, Erica Madonna ${ }^{1,2}$, Kasja Witlox ${ }^{1,3}$, Sylvaine Ferrachat ${ }^{1}$, Heini Wernli $^{1}$, and Ulrike Lohmann ${ }^{1}$ \\ ${ }^{1}$ ETH Zurich, Institute for Atmospheric and Climate Science, Zurich, Switzerland \\ ${ }^{2}$ Geophysical Institute, University of Bergen and Bjerknes Centre for Climate Research, Bergen, Norway \\ ${ }^{3}$ Zurich Insurance Company Ltd, Zurich, Switzerland
}

Correspondence to: Hanna Joos (hanna.joos@env.ethz.ch)

Received: 10 August 2016 - Discussion started: 21 October 2016

Revised: 24 March 2017 - Accepted: 17 April 2017 - Published: 22 May 2017

\begin{abstract}
While there is a clear impact of aerosol particles on the radiation balance, whether and how aerosol particles influence precipitation is controversial. Here we use the ECHAM6-HAM global climate model coupled to an aerosol module to analyse whether an impact of anthropogenic aerosol particles on the timing and amount of precipitation can be detected in North Pacific warm conveyor belts. Warm conveyor belts are the strongest precipitationproducing airstreams in extratropical cyclones and are identified here with a Lagrangian technique, i.e. by objectively identifying the most strongly ascending trajectories in North Pacific cyclones. These conveyor belts have been identified separately in 10-year ECHAM6-HAM simulations with present-day and pre-industrial aerosol conditions. Then, the evolution of aerosols and cloud properties has been analysed in detail along the identified warm conveyor belt trajectories. The results show that, under present-day conditions, some warm conveyor belt trajectories are strongly polluted (i.e. high concentrations of black carbon and sulfur dioxide) due to horizontal transport from eastern Asia to the oceanic region where warm conveyor belts start their ascent. In these polluted trajectories a weak delay and reduction of precipitation formation occurs compared to clean warm conveyor belt trajectories. However, all warm conveyor belts consist of both polluted and clean trajectories at the time they start their ascent, and the typically more abundant clean trajectories strongly reduce the aerosol impact from the polluted trajectories. The main conclusion then is that the overall amount of precipitation is comparable in pre-industrial conditions, when all warm conveyor belt trajectories are clean, and in
\end{abstract}

present-day conditions, when warm conveyor belts consist of a mixture of clean and polluted trajectories.

\section{Introduction}

The interaction of aerosol particles with clouds and radiation is the largest source of uncertainty for estimating the total anthropogenic forcing since pre-industrial times (Boucher et al., 2013). Anthropogenic aerosol particles such as sulfate and carbonaceous aerosols have substantially increased the global mean burden of aerosol particles from pre-industrial times to the present day. While the largest increases in aerosol emissions in the 20th century were located in Europe and North America, nowadays anthropogenic aerosol emissions are highest in south-eastern Asia (Granier et al., 2011; Klimont et al., 2013).

Aerosol particles affect the vertical extent, lifetime, phase and optical properties of clouds by acting as cloud condensation or ice nuclei. Whether aerosol particles also impact precipitation and, if so, how, is controversial. The scientific review of aerosol pollution impact on precipitation by Levin and Cotton (2008a) concluded that clear causal relationships between an increase in aerosol particles and changes in precipitation are difficult to identify and even the sign of the change in precipitation is uncertain. Based on Monte-Carlo simulations Yan et al. (2015) showed that, due to the uncertainties in representing cloud microphysics in models, it is a challenge to quantify the impact of aerosols on clouds. Most 
studies (both observational and numerical) have analysed the possible impact of aerosol particles on low-level nonprecipitating or slightly precipitating liquid water clouds. Some studies suggest that air pollution delays the onset of orographic precipitation whereas the effect of cities on precipitation cannot be unambiguously related to air pollution (Levin and Cotton, 2008b).

Studies evaluating a possible aerosol effect on precipitation can be categorized among others into those that examine the weekly cycle of aerosols and precipitation, those analysing aerosol effects on precipitation from convective clouds and those from cyclones (extratropical cyclones and hurricanes). They can be summarized as follows.

Weekly cycles in cloud properties and precipitation have been reported as evidence for an aerosol effect on precipitation because of the weekly cycle in aerosols and their precursor emissions (e.g. Baeumer and Vogel, 2007; Rosenfeld and Bell, 2011). However, many of these studies were disputed because of weaknesses in their applied statistical methods, their methodology or because the results could have been obtained by a simultaneous response of aerosol particles and precipitation to meteorological conditions (e.g. SanchezLorenzo et al., 2012; Yuter et al., 2013; Boucher and Quaas, 2013).

Aerosol effects on convective clouds also found contradictory results. In the case of pyrocumulus, which are characterized by extreme air pollution and extremely high aerosol concentrations, Reutter et al. (2014) found that the onset of precipitation is delayed and its intensity is reduced with increasing aerosol concentration. On the contrary, Rosenfeld et al. (2008) proposed an invigoration of convective clouds due to pollution. The growth of cloud droplets into raindrops is slower in polluted clouds, which consist of more but smaller cloud droplets, than in clean clouds. This delays the formation of warm rain and more cloud water is available for freezing in polluted deep convective clouds. The increased latent heat release may invigorate polluted convective clouds and lead to overall more precipitation from them.

Igel et al. (2013) analysed the impact of aerosol particles on precipitation in the vicinity of a warm front. They found a shift in location caused by a delay of the onset of precipitation with increasing aerosol concentration, but the total precipitation from the warm front remained relatively constant. They attributed the rather constant total precipitation to a buffering effect. Smaller cloud droplets due to increased aerosol concentrations in the mixed-phase region of the cloud, where cloud droplets and ice crystals coexist, caused a decreased riming efficiency (Borys et al., 2003) but led to enhanced growth by diffusion. Thompson and Eidhammer (2014) studied the impact of aerosol particles on precipitation from a large winter cyclone. They also observed a delay in warm-phase precipitation formation, but an increase in snow to the north of the warm front. They concluded that aerosol impacts were much stronger in areas with light precipitation rates than in those with higher precipitation rates.
The present study extends the above studies on the aerosol impact on one extratropical cyclone to a climatology of precipitation in extratropical cyclones in the North Pacific using the ECHAM6-HAM global climate model. We chose the North Pacific because of the increase in anthropogenic emissions over south-eastern Asia and because the prevailing westerly winds carry these anthropogenic aerosols and their precursors over the North Pacific. Therefore, we expect to see large differences in aerosol burden and aerosol optical depth between present-day and pre-industrial conditions in this region. In addition, low-pressure systems frequently form here (e.g. Chen et al., 1991). Thus if an impact of anthropogenic aerosol particles on low-pressure systems can be identified somewhere, then the North Pacific is the region to study this.

The effect of Asian pollution on clouds in the North Pacific region has been investigated in different studies. Wang et al. (2014a) showed that anthropogenic aerosols lead to changes in the cloud microphysical properties and the radiative forcing at the top of atmosphere. Furthermore, they stated that an increase in cloud top height indicated invigorated midlatitude cyclones connected to an overall increase in precipitation. Also, Zhou and Deng (2013) found that higher anthropogenic aerosol emissions lead to an increase in the amplitude of synoptic eddies and subsequently to an increase in surface precipitation. An intensification of the Pacific storm track is also found in Zhang et al. (2007). They argued that the wintertime Pacific is highly vulnerable to cloud-aerosol interactions because of the coupling between the Pacific storm track and Asian pollution outflow.

In our study, we specifically focus on the so-called warm conveyor belt (WCB) airstream, which is a typical feature of (intense) extratropical cyclones. By focusing on the WCB we investigate aerosol effects in a relatively well-defined flow setting, in contrast to other climate model studies that consider the aerosol effect on total precipitation without distinguishing different categories of weather systems that produce precipitation (Denman et al., 2007).

WCBs are coherent moist ascending airstreams in extratropical cyclones associated with the formation of elongated frontal cloud bands and intense precipitation (e.g. Browning, 1986). They can be objectively identified with the aid of trajectory calculations. Wernli and Davies (1997) showed that WCBs are formed by moist boundary layer air parcels that ascend by about $600 \mathrm{hPa}$ or more within a time period of 2 days. Thereby intense cloud formation and latent heating occurs in WCB trajectories, leading to a typical loss of specific humidity of more than $10 \mathrm{~g} \mathrm{~kg}^{-1}$ and an increase of potential temperature of about $20 \mathrm{~K}$ (Madonna et al., 2014). Initially, WCB air parcels are cloud free, then liquid water clouds form in the early part of the ascent leading to mixed-phase clouds in the mid-troposphere and pure ice clouds in the WCB outflow at upper-tropospheric levels (about $350 \mathrm{hPa}$ with temperatures below $-30^{\circ} \mathrm{C}$ ) (Joos and Wernli, 2012; MartinezAlvarado et al., 2014). WCBs are intrinsic subsynoptic scale 
features of extratropical cyclones and therefore climatological frequency maxima of WCBs occur in the extratropical storm track regions (Eckhardt et al., 2004; Madonna et al., 2014). In these regions more than half of total precipitation and up to $90 \%$ of extreme precipitation events are associated with WCBs (Pfahl et al., 2014). In particular, in the western North Pacific just to the east of Japan, more than $60 \%$ of the climatological precipitation and more than $90 \%$ of the precipitation extremes (defined as events above the 99th percentile) are collocated with WCBs (Pfahl et al., 2014). Furthermore, due to the strong ascent, WCBs connect the different tropospheric layers and are therefore important for the transport of pollution from the boundary layer to the middle/upper troposphere (Stohl, 2001; Ding et al., 2009). By investigating precipitation formation in $\mathrm{WCBs}$ in the western North Pacific, this study examines potential effects of anthropogenic aerosol emissions within the highly relevant category of extratropical weather systems.

The paper is organized as follows. In Sect. 2, the data and methods are introduced. Section 3 gives an overview of the simulations and in Sect. 4, a case study of a WCB is briefly discussed. In Sect. 5, the influence of aerosol particles on precipitation in WCBs is examined statistically for the entire 10-year climatology. The conclusions follow in Sect. 6.

\section{Data and methods}

\subsection{ECHAM simulations}

The version of ECHAM6-HAM used in this study (ECHAM6.1-HAM2.2) has been described in Neubauer et al. (2014). ECHAM6 (Stevens et al., 2013) solves prognostic equations for temperature, surface pressure, divergence and vorticity in spectral space with a triangular truncation. ECHAM6 has a fractional cloud cover scheme that diagnoses fractional cloud cover from relative humidity once a critical relative humidity is exceeded following Sundqvist et al. (1989). In contrast to the one-moment cloud microphysics scheme for stratiform clouds that is used in the standard model ECHAM6, a two-moment cloud microphysics scheme is used in this study (Lohmann and Hoose, 2009). It consists of prognostic equations for the number and mass concentrations of cloud droplets and ice crystals next to specific humidity.

The second version of the two-moment aerosol scheme Hamburg Aerosol Module (HAM2) predicts the aerosol mixing state in addition to the aerosol mass and number concentrations (Zhang et al., 2012). The size distribution is represented by a superposition of seven log-normal modes including the major global aerosol compounds sulfate, black carbon, organic carbon, sea salt and mineral dust in different mixing states. The latest version of HAM (HAM2.2) used here includes a size-dependent in-cloud scavenging parameterization (Croft et al., 2010). ECHAM6 with the two- moment cloud microphysics scheme is coupled to HAM by activation of aerosol particles with radii larger than $35 \mathrm{~nm}$ into cloud droplets (Lin and Leaitch, 1997), by homogeneous freezing of supercooled solution droplets for the formation of cirrus clouds (Lohmann et al., 2008) and heterogeneous nucleation (immersion freezing of internally mixed mineral dust and black carbon aerosols and contact freezing of externally mixed mineral dust particles) in mixed-phase clouds (Hoose et al., 2008). Thus, the impact of aerosols on warm, mixed-phase and ice clouds can be studied using ECHAM6HAM.

A mass flux scheme is employed for shallow, mid-level and deep convection (Tiedtke, 1989) with modifications for deep convection according to Nordeng (1994). The scheme is based on steady-state equations for mass, heat, moisture, cloud water and momentum for an ensemble of updraughts and downdraughts, including turbulent and organized entrainment and detrainment. Detrainment of cloud liquid water and ice in the upper part of the convective updraughts is used as a source term in the stratiform cloud water equations. Aerosol effects on convective clouds are not included, except that the cloud droplet number concentration from detrainment from convective clouds depends on the aerosol number concentration of internally mixed aerosol particles with radii larger than $25 \mathrm{~nm}$ at the cloud base of the convective clouds.

The ECHAM6-HAM simulations have been carried out in T63 horizontal resolution $\left(1.875^{\circ} \times 1.875^{\circ}\right)$ on 31 vertical levels with the model top at $10 \mathrm{hPa}$ and a time step of $12 \mathrm{~min}$. All simulations used present-day climatological sea surface temperature (averaged over the years 1979-2008) and sea-ice extent and have been integrated for 10 years after a spin-up period of 3 months. The greenhouse gas concentrations are constant and correspond to values of the year 2000. The present-day simulations conducted with ECHAM6-HAM use aerosol emissions of sulfate, black and organic carbon from the AeroCom Phase II database for the year 2000 (Lamarque et al., 2010). Mineral dust and sea salt emissions are calculated online based on near-surface wind speed. The sources of black carbon aerosol particles are fossil fuel combustion, biofuel and wildfires. Only a fraction of the wildfires are of natural origin; the rest of the emissions are due to anthropogenic activities. To isolate the total anthropogenic aerosol effect, all simulations were repeated with aerosol emissions of sulfate, black and organic carbon for pre-industrial times representing the year 1850 (Lamarque et al., 2010). The two simulations will be referred to as the present-day (PD) and the pre-industrial (PI) simulations.

\subsection{Calculation of WCBs}

In order to identify WCBs, trajectories are calculated with the Lagrangian analysis tool LAGRANTO (Wernli and Davies, 1997) and the same procedure is used as in Madonna et al. (2014). Forward trajectories are calculated for a time period of $48 \mathrm{~h}$, using wind fields from the ECHAM6-HAM output 
every $6 \mathrm{~h}$. Trajectories are started every $6 \mathrm{~h}$ during the entire simulation period (10 years). In the vertical, trajectories are started every $20 \mathrm{hPa}$ in the lower troposphere between 1050 and $790 \mathrm{hPa}$, and horizontally, they are started every $150 \mathrm{~km}$ in the whole of the North Pacific $\left(100-260^{\circ} \mathrm{E}, 0-90^{\circ} \mathrm{N}\right)$. As mentioned in the introduction, only trajectories with an ascent of more than $600 \mathrm{hPa}$ in $48 \mathrm{~h}$ are selected as WCB trajectories. Additionally, WCB trajectories must rise in the vicinity of an extratropical cyclone to distinguish them, for example, from organized deep convection. Extratropical cyclones have been identified using the method described in Wernli and Schwierz (2006). Therein, a surface cyclone is defined as a local sea level pressure (SLP) minimum surrounded by the outermost closed SLP contour. The area inside such a closed contour is then defined as an extratropical cyclone. WCB trajectories have to cross the area of a surface cyclone at least once during their $48 \mathrm{~h}$ ascent. For a more detailed description of the identification of WCB trajectories see Madonna et al. (2014). The resulting climatology of WCB starting points for the winter months is shown for both simulations in Fig. 1a, b. The distributions are similar in the PD and PI simulations and also agree well with the reference ERA-Interim-based WCB climatology (Fig. 1c), in particular in the western and central North Pacific, which is the region of interest in this study.

For a more detailed analysis of the WCB trajectories (see Sect. 5), different variables of interest are traced along the trajectories. For our study, in addition to the position of the trajectories (longitude, latitude and pressure), this includes the variables potential temperature $(\theta)$, specific humidity $(q)$, liquid water content (LWC), ice water content (IWC), cloud droplet number concentration (CDNC), precipitation (the sum of large scale and convective), black carbon (BC) aerosol mass mixing ratio and sulfur dioxide $\left(\mathrm{SO}_{2}\right)$. The $\mathrm{BC}$ mass mixing ratio is shown as a sum of all $\mathrm{BC}$ mass mixing ratios in the soluble Aitken, accumulation and coarse modes. Please also note that the precipitation field is two-dimensional and therefore the interpolated precipitation value at the position of a WCB trajectory represents the precipitation reaching the surface below the trajectory, whereas all other variables are three-dimensional and the interpolated values represent the value of this field at the trajectory position itself. The selection of WCBs and the tracing of variables is performed for both the PI and PD simulations.

\subsection{Study design}

Our main focus is on studying WCBs that ascend in the western North Pacific in winter (DJF), i.e. in a region where they can be potentially influenced by strong anthropogenic emissions. Most WCBs (each consisting of many trajectories) start their ascent over the ocean (Fig. 1), whereas emissions occur over the continent further to the west. This constellation leads to a high variability of the concentration of anthropogenic pollutants ( $\mathrm{SO}_{2}$ and $\mathrm{BC}$ aerosols) in the inflow of North Pacific WCBs, as some WCBs contain only clean ma- rine boundary layer air and others contain also highly polluted air parcels of continental origin. To cope with this variability, we quantified the concentration of $\mathrm{SO}_{2}$ at the start of the ascent for every identified WCB trajectory and use this information to classify $10 \%$ of the trajectories with the lowest (highest) $\mathrm{SO}_{2}$ concentrations as clean (polluted) trajectories.

However, the cleanest and the most polluted WCB trajectories in the western North Pacific tend to start at slightly different latitudes (not shown) and are therefore also characterized by slightly different initial specific humidity values, which renders a direct comparison of the evolution of the two categories of WCB trajectories difficult. Since, at the beginning of the ascent, the cleanest WCB trajectories are on average moister than the most polluted ones, it would be impossible to attribute differences in the microphysical evolution along the two categories of WCB trajectories to either the initial moisture value or the different aerosol concentrations. To circumvent this problem, we restricted the selection of WCB trajectories to a relatively small area and to a narrow range of initial specific humidity values. The region considered for the start of the WCB ascent extends from $140-160^{\circ} \mathrm{E}$ and 20 $40^{\circ} \mathrm{N}$, which contain the climatological maximum of $\mathrm{WCB}$ starting points in winter (see Fig. 1). In order to analyse WCB trajectories that start with similar initial specific humidity values, only WCB trajectories with an initial specific humidity between 8 and $10 \mathrm{~g} \mathrm{~kg}^{-1}$ will be considered for statistical analysis. Thus, in the PD simulation, WCB trajectories are selected if they fulfil the following criteria: i) they start their ascent in the box outlined above, and ii) their initial specific humidity value is between 8 and $10 \mathrm{~g} \mathrm{~kg}^{-1}$. Additionally, clean and polluted trajectories are then selected based on their $\mathrm{SO}_{2}$ mass mixing ratio at time $0 \mathrm{~h}$, i.e. at the beginning of the ascent. Trajectories with a $\mathrm{SO}_{2}$ mass mixing ratio below $51.6 \mathrm{pg} \mathrm{kg}^{-1}$ or above $350.1 \mathrm{pg} \mathrm{kg}^{-1}$ are selected, which corresponds to the $10 \%$ cleanest and the $10 \%$ most polluted WCB trajectories, respectively. In contrast, in the PI simulation, the $10 \%$ WCB trajectories with the closest initial $\mathrm{SO}_{2}$ mass mixing ratio to the mean (45-55 percentile) have been selected. This selection procedure yields $\sim 2300 \mathrm{WCB}$ trajectories in each category, which allows for a meaningful statistical analysis.

\section{Overview on pre-industrial and present-day simulations}

Before evaluating the WCBs, some general characteristics of the ECHAM6-HAM simulations are presented and compared with ERA-Interim reanalyses (Dee et al., 2011). Figure $2 \mathrm{a}-\mathrm{c}$ shows the winter mean field of SLP and potential temperature at $850 \mathrm{hPa}$ for the $\mathrm{PI}$ and $\mathrm{PD}$ simulations and ERA-Interim. The main features in the time mean are the general southward-oriented gradient in SLP and potential temperature, the Aleutian low with a central pressure 

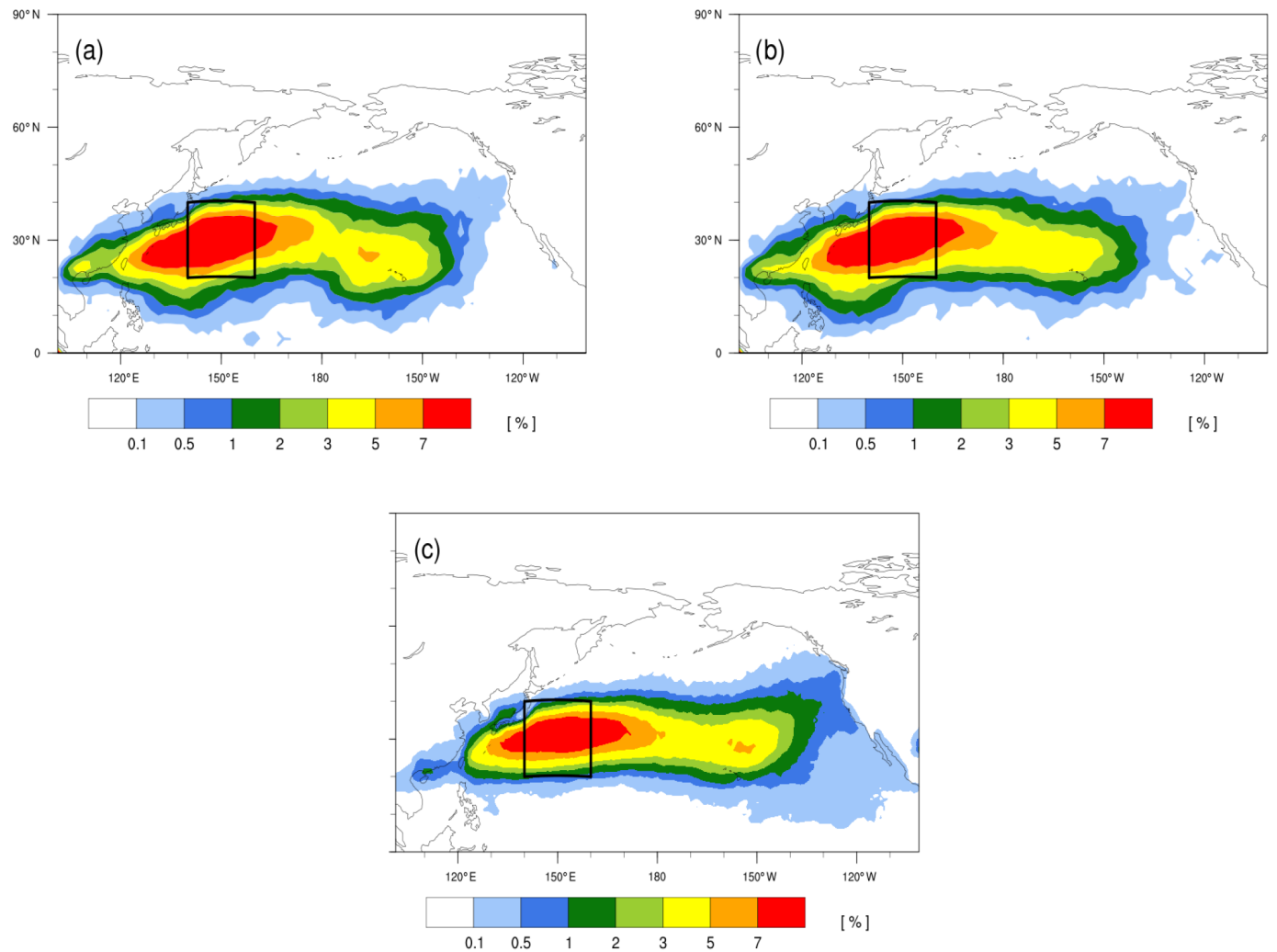

Figure 1. Climatological frequency of WCB starting points in winter (DJF) for PI (a), PD (b) and ERA-Interim (c). Colours represent the relative frequency (in \%) of WCB trajectories at each grid point. The black box denotes the starting region of the WCBs considered in the analysis below.

of about $1000 \mathrm{hPa}$ in the simulations and $995 \mathrm{hPa}$ in ERAInterim, and the strong horizontal temperature gradient in the region of Japan. The fields for the two simulations are almost identical, which reveals that the different aerosol emissions in the two simulations have no effect on the time mean SLP distribution and baroclinicity. Compared to ERAInterim the ECHAM simulations underestimate the intensity of the Aleutian Low, which is most likely due to the wellknown problem of fairly coarse global climate models to not resolve the peak intensity of extratropical cyclones (Jung et al., 2006). Another difference between the simulations and ERA-Interim appears for the tropical temperatures, which are about $5 \mathrm{~K}$ too low in the simulations, consistent with the underestimation of tropical precipitation. This shortcoming of climate models can be related to the parameterization of tropical convection and can be improved if the vertical resolution is increased (Stevens et al., 2013).

Marked differences between the two simulations occur when considering aerosol optical depth (AOD) and liquid water path (LWP, vertically integrated liquid water content) (see Fig. 2d, e). By design, the PD simulation shows much higher values of AOD over China, Japan and the nearby oceanic regions than the PI simulation. In the WCB starting region defined in the previous section (black box in Fig. 2) the winter mean values of AOD vary roughly between 0.1 and 0.15 in the PI simulation and between 0.15 and 0.2 in the PD simulation, indicating that the mean AOD in the WCB starting region of interest is increased by less than $50 \%$ in PD compared to PI, but this increase is of course much larger over the main industrial areas. The increase in AOD is caused by an increase in accumulation and Aitken mode aerosol particles that serve as cloud condensation nuclei $(\mathrm{CCN})$ and cause liquid water clouds to consist of more cloud droplets. Because the available water vapour remains the same, these cloud droplets do not grow as large. In a cloud consisting of more but smaller cloud droplets, the collision efficiency between cloud droplets is reduced and hence their growth to precipitation-sized drops is retarded (Lohmann et al., 2016). In order to produce rain in a polluted cloud, the liquid water content needs to adjust to higher values. This is visible in the elevated values of the liquid water path in the PD simulation.

Considering again the WCB starting region, the increase of the LWP amounts to about $30 \%$. Further downstream, the differences are small, illustrating the limited scale of the region impacted by the anthropogenic aerosol emissions. For the ice water path, the two simulations show very similar mean values (not shown). Here, no comparison is shown with ERA-Interim because different microphysical schemes 

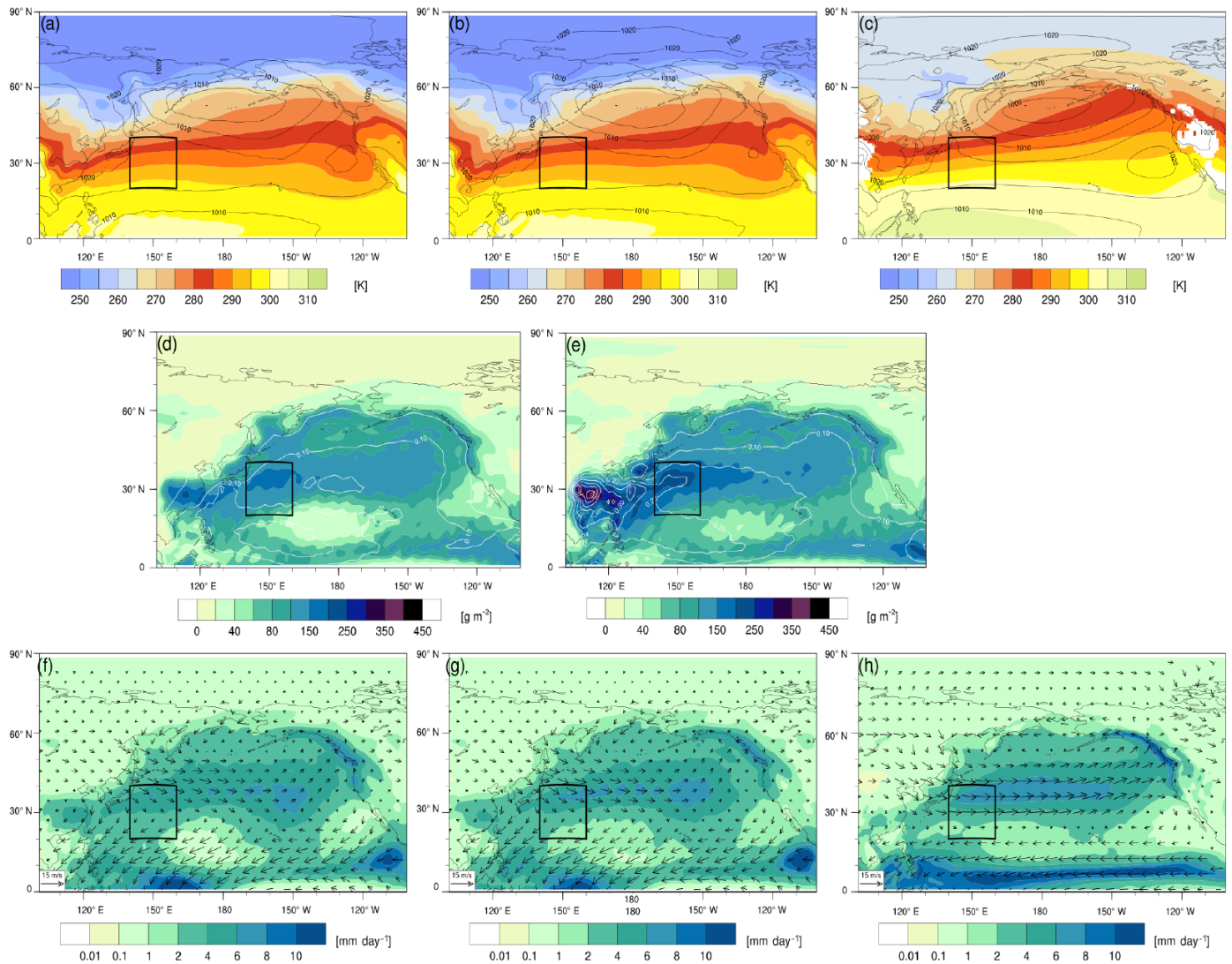

Figure 2. Winter mean SLP (contours) and potential temperature (shades) at $850 \mathrm{hPa}$ for PI (a) and PD (b) simulations and ERA-Interim (c). Liquid water path (shading) in $\mathrm{g} \mathrm{m}^{-2}$ and aerosol optical depth (white contours) for PI (d) and PD (e) simulations. Total precipitation (large scale and convective in $\mathrm{mm}_{\text {day }}{ }^{-1}$ ) and winds at $850 \mathrm{hPa}$ in PI (f) and PD (g) simulations and ERA-Interim (h). The black box, extending from $140-160^{\circ} \mathrm{E}$ and $20-40^{\circ} \mathrm{N}$, denotes the starting region of the considered WCBs.

lead to fairly large differences in liquid and ice water paths, which, however, cannot be interpreted as a model shortcoming. The ECHAM6-HAM microphysics is more sophisticated and complete compared to ERA-Interim and therefore, for these parameters, we cannot regard ERA-Interim as a reference.

Finally, Fig. 2f, g shows the winter average surface precipitation and $850 \mathrm{hPa}$ horizontal wind vectors for the two simulations and ERA-Interim (Fig. 2h). Consistent with the differences discussed above, the simulations underestimate tropical convection in particular in the western Pacific, but north of $20^{\circ} \mathrm{N}$ the comparison with ERA-Interim shows only a weak underestimation. The lower values along the western flank of the Rocky Mountains can be explained by the lower topography in the coarser resolution model. The lower tropospheric wind fields show the correct pattern in the simulations; however, in agreement with the errors in the SLP field, the westerlies in the main storm track region are too weak. Differences between the two simulations are generally small. The main differences appear for precipitation over China (where PI is slightly wetter) and in the central North Pacific (where PD has slightly more precipitation on aver-
Table 1. AOD, LWP, CDNC and large-scale precipitation averaged over the whole of the North Pacific (same area as shown in Fig. 2) for the winter months.

\begin{tabular}{lcrrr}
\hline Simulation & AOD & $\begin{array}{r}\text { LWP } \\
{\left[\mathrm{g} \mathrm{m}^{-2}\right]}\end{array}$ & $\begin{array}{r}\text { CDNC } \\
{\left[\mathrm{cm}^{-3}\right]}\end{array}$ & $\begin{array}{r}\text { Large-scale precip. } \\
{\left[\mathrm{mm} \mathrm{day}^{-1}\right]}\end{array}$ \\
\hline PI & 0.07 & 56.2 & 45.7 & 1.38 \\
PD & 0.09 & 70.2 & 66.1 & 1.38 \\
\hline
\end{tabular}

age). Table 1 shows the domain average values of AOD, LWP, CDNC and surface precipitation. In the mean it can be seen that the AOD, LWP and CDNC increase from PI to PD whereas the precipitation stays almost identical. This can be explained by the fact that due to the reduced efficiency in precipitation formation caused by the strong increase in CDNC, more condensate stays in the atmosphere and leads to an increase in LWP. 


\section{WCB case study}

We first present an example WCB to illustrate the method and the evolution of $\mathrm{SO}_{2}$ along the pathway of an initially strongly polluted WCB. Figure 3 shows one WCB identified with the method described above that occurred in the PD simulation in February. Thus, at the shown point in time, 66 trajectories fulfill the criteria of an ascent exceeding $600 \mathrm{hPa}$ in $48 \mathrm{~h}$ in the vicinity of an extratropical cyclone. All of the shown trajectories belong to one and the same WCB. The 66 WCB trajectories are shown as 66 individual lines in Fig. 3a, and $\mathrm{b}$ indicates their fast ascent between times 0 and $48 \mathrm{~h}$ from, on average, 950 to $350 \mathrm{hPa}$. During their ascent the WCB air parcels move from their starting region to the east of Japan $\left(35^{\circ} \mathrm{N}\right)$ to their outflow region over the central North Pacific $\left(50-60^{\circ} \mathrm{N}\right.$, Fig. 3a). During the 2 days prior to their ascent, i.e. from time -48 to $0 \mathrm{~h}$, the WCB trajectories are fairly stationary and experience, on average, a slow descent from 900 to $950 \mathrm{hPa}$ (Fig. 3b). The $\mathrm{SO}_{2}$ mass mixing ratio (see colouring of trajectories) shows very high values for most of the trajectories before the ascent. A substantial fraction (46 of the 66 trajectories, i.e. $70 \%$ ) exceeds the threshold to be classified as "polluted" (see Sect. 2.3). During the ascent the $\mathrm{SO}_{2}$ values rapidly decrease for three reasons: $\mathrm{SO}_{2}$ can be oxidized to sulfate in the gas phase and subsequently serve as $\mathrm{CCN}$, it can be dissolved in cloud droplets and oxidized in the aqueous phase (Seinfeld and Pandis, 1998), or it can condense on other preexisting aerosol particles.

It is important to note that such a configuration where the majority of WCB trajectories are strongly polluted is rare (see further analysis below). More typically, whenever a WCB (consisting of many trajectories) starts, a much smaller fraction of WCB trajectories is polluted due to the highly variable inflow of air parcels into a WCB.

\section{Statistical analysis}

In this section, first the general characteristics of the identified WCB trajectories starting from the region defined above are described, followed by a detailed comparison of so-called clean and polluted WCB trajectories in the simulations. It is our aim to compare, for PI WCB trajectories and for clean and polluted PD WCB trajectories, the evolution of LWC and IWC and the associated surface precipitation along the WCB trajectories in order to identify potential effects of the different initial aerosol concentrations on clouds and precipitation.

In Fig. 4, the average evolution of potential temperature, specific humidity, BC, CDNC, cloud condensate (sum of LWC and IWC) and surface precipitation is shown as a function of pressure, separately for the three categories of WCB trajectories. The evolution of potential temperature and specific humidity (Fig. 4a, b) is very similar for the PD clean, PD polluted and PI trajectories. The trajectories start their ascent between 290 and $295 \mathrm{~K}$ and reach the upper troposphere (i.e. $300 \mathrm{hPa}$ ) on the $315 \mathrm{~K}$ isentrope. The initial moisture is between 8 and $10 \mathrm{~g} \mathrm{~kg}^{-1}$ (by design; see Sect. 2.3) and decreases rapidly along the ascending trajectories at a very similar rate. This nicely shows that the overall meteorological conditions and the large-scale ascent of the WCB trajectories are comparable between the three categories and should not be responsible for potential differences in the formation of precipitation.

The evolution of $\mathrm{BC}$ (Fig. 4c) and $\mathrm{SO}_{2}$ (not shown) along the considered trajectory samples, however, reveals huge differences. The polluted trajectories exhibit high BC values at low levels with values between 50 and $130 \mathrm{pg} \mathrm{kg}^{-1}$. Because the internally mixed $\mathrm{BC}$ aerosols serve as $\mathrm{CCN}$ and are activated to cloud droplets during the ascent, the $\mathrm{BC}$ mass mixing ratio strongly decreases with height. The PD clean and PI trajectories show much lower BC values around 10$20 \mathrm{pg} \mathrm{kg}^{-1}$ being 5 to 10 times smaller than the polluted PD trajectories and even their $25-75 \%$ percentiles do not overlap below $750 \mathrm{hPa}$. The clean PD trajectories have twice as much $\mathrm{BC}$ as the ones in the PI simulation with a slight overlap of their $25-75 \%$ percentiles. This difference indicates that clean present-day conditions cannot be taken as a surrogate for pre-industrial conditions. For $\mathrm{SO}_{2}$, PI and PD clean trajectories show a very similar evolution, whereas the polluted trajectories have much more $\mathrm{SO}_{2}$ in the lower troposphere up to $\sim 700 \mathrm{hPa}$ (not shown). The overall differences in $\mathrm{SO}_{2}$ between the PD polluted and PI trajectories are even larger than for BC (Table 2).

The cloud droplet number concentration also decreases with decreasing pressure (Fig. 4d), partly because of the decrease of $\mathrm{CCN}$ with decreasing pressure and partly because the formation of precipitation increases with decreasing pressure due to the higher liquid and ice water contents (Fig. 4e) and the larger cloud droplets and ice crystals. The differences in CDNC between PD polluted and PD clean are much smaller than in BC, partly because in ECHAM-HAM we assume that each cloud has a minimum CDNC of $40 \mathrm{~cm}^{-3}$. Furthermore, other aerosol species can also act as $\mathrm{CCN}$ and therefore the CDNC cannot be determined by the BC concentration only. Apart from that we see the same differences as in $\mathrm{BC}$, with the PI trajectories having the smallest CDNC and the PD polluted trajectories the highest CDNC.

Regarding the highest CDNC values in the PD polluted trajectories, the median value of total condensate, i.e. the sum of the liquid and ice water content (LWC + IWC) (see Fig. 4e), is larger in the PD simulation, but the differences between the three sets of WCB trajectories are much smaller and the $25-75 \%$ percentiles strongly overlap. The total condensate peaks at $750 \mathrm{hPa}$ in all simulations. At lower pressure levels the cloud condensate is reduced on the one hand due to precipitation formation becoming more efficient higher in the cloud and on the other hand due to the smaller specific humidity at colder temperatures, i.e. smaller condensation/deposition rates. While the PD clean trajectories were in between the PI and PD polluted trajectories in terms of BC 

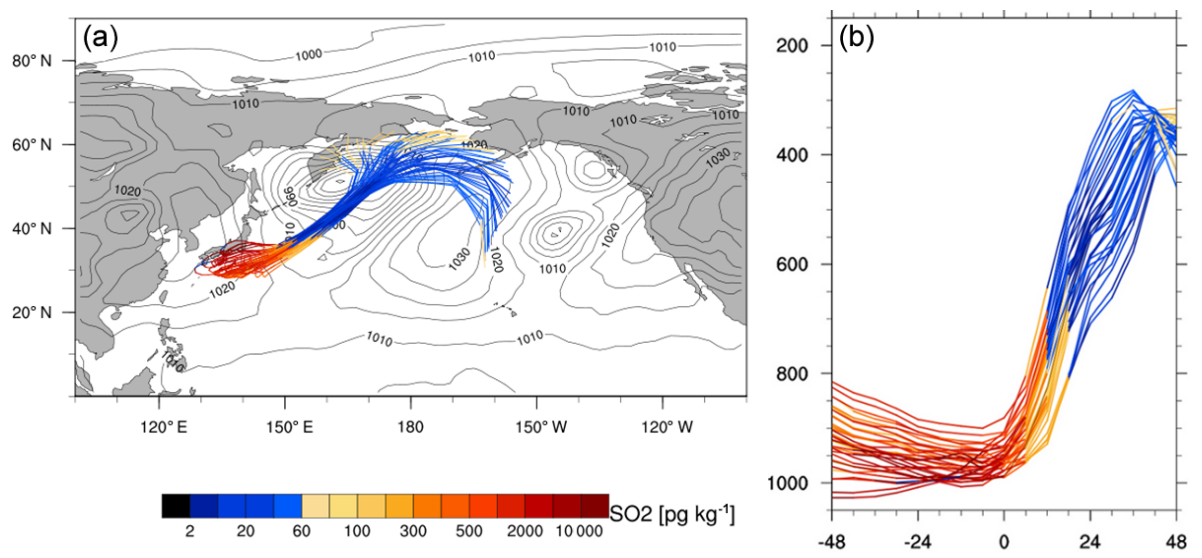

Figure 3. Case study of a WCB consisting of 66 trajectories with $70 \%$ polluted trajectories calculated in the PD simulation. Panel (a) shows the path of the 4-day WCB trajectories (plotted from time -48 to $+48 \mathrm{~h}$, where $0 \mathrm{~h}$ denotes the start of the $48 \mathrm{~h}$ ascent), coloured with their $\mathrm{SO}_{2}$ mass mixing ratio (in pg kg${ }^{-1}$ ) and SLP (black contours, in $\mathrm{hPa}$ ) at time $+36 \mathrm{~h}$. (b) The same WCB trajectories but showing pressure (in $\mathrm{hPa}$ ) as a function of time (in hours), coloured with the $\mathrm{SO}_{2}$ mass mixing ratio.

and CDNC, they now fall on top of the PD polluted ones. Note that the case-to-case variability in every subsample is larger than the systematic difference between them as to be expected due to the high variability in the associated cyclone dynamics.

Precipitation formation depends more strongly on the liquid and ice water contents than inversely on the number concentrations of cloud droplets and ice crystals. Therefore its maximum at $700 \mathrm{hPa}$ (Fig. 4f) is more determined by the maximum in liquid and ice water content than by CDNC and ice crystal number concentration. At $900 \mathrm{hPa}$ the median precipitation rate is higher in the PD clean and the PI trajectories than in the PD polluted trajectories, although the variability between individual trajectories is again rather large and the $25-75 \%$ percentiles strongly overlap. At pressures below $470 \mathrm{hPa}$, the median precipitation rate of the PD polluted trajectories crosses that of the PI trajectories, pointing to a delay in precipitation formation in the PD polluted WCBs. As summarized in Table 2 most of the precipitation falls as stratiform large-scale precipitation. It is largest in the PD clean trajectories where the average specific humidity is smallest, i.e. where more water exists in the liquid and ice phase. One could also argue that the initial $\mathrm{BC}$ concentration is determined by the initial precipitation. Less precipitation in the PD polluted trajectories leads to a reduced scavenging and therefore to an increased BC concentration. In order to exclude this effect, we compared all trajectories that start with similar initial precipitation. However, the results (not shown) confirm the behaviour shown in Fig. 4. We therefore conclude that it is the aerosol concentration that influences the precipitation and not the other way round.

In order to investigate the effect of the differences in the aerosol loadings on the precipitation formation, phase space diagrams of $q$ and total condensate (LWC + IWC) as a function of the total precipitation are shown in Fig. 5, which makes it possible to directly link moisture and total condensate to the associated precipitation.

The amount of condensate that can be formed is determined by the large-scale ascent, the availability of moisture and the conversion efficiency from condensate to precipitation. Figure 5a, nicely shows that for all three cases the evolution of $q$ is very similar. All trajectories start with a specific humidity of $\sim 9 \mathrm{~g} \mathrm{~kg}^{-1}$ followed by a strong decrease at very similar rates. However, the precipitation falling out of these trajectories is reduced for the PD polluted subsample and the peak value reaches less than $50 \mathrm{~mm} \mathrm{day}^{-1}$ in the PD polluted case whereas it reaches $55 \mathrm{~mm} \mathrm{day}^{-1}$ in the PD clean and PI case. This can also be seen in Fig. 5b, where the total condensate is shown as a function of total precipitation. However, the total amount of total condensate also varies between PD and PI cases. With decreasing pressure, total condensate increases up to a height of $750 \mathrm{hPa}$. For the PD clean and PD polluted trajectories, this increase is steeper and the total condensate peaks around $140 \mathrm{mg} \mathrm{kg}^{-1}$, whereas it increases more slowly and only reaches $\sim 120 \mathrm{mg} \mathrm{kg}^{-1}$ for the PI case.

Because of the much lower availability of $\mathrm{CCN}$ in the PI run, fewer cloud droplets form that can grow to larger sizes. These larger and fewer cloud droplets form precipitation quite efficiently, leading to a fast removal of condensate from the atmosphere. This effect can be seen in Fig. 5b (black line) where the increase in total condensate is less steep and the maximum value is smaller compared to PD polluted/clean. On the contrary, in the PD clean case, the mass mixing ratio of $\mathrm{BC}$ is already twice as large compared to PI. This increase in the availability of CCN leads to more and smaller cloud droplets and reduces the efficiency of precipitation formation. Therefore, less precipitation is reaching the ground and more condensate remains in the atmosphere (see brown and blue line). In the PD polluted subsample, where 
Table 2. Different parameters averaged along all WCB trajectories for the PI, PD clean and PD polluted WCB trajectories. The numbers are the mean, and in brackets the 25 th and 75 th percentiles.

\begin{tabular}{|c|c|c|c|}
\hline WCB & PI & PD clean & PD polluted \\
\hline$q\left[\mathrm{~g} \mathrm{~kg}^{-1}\right]$ & $3.7(2.8 ; 4.5)$ & $3.4(2.5 ; 4.0)$ & $3.6(2.7 ; 4.4)$ \\
\hline Conv. precip. $\left[\mathrm{mm} \mathrm{day}^{-1}\right]$ & $2.4(0.4 ; 3.2)$ & 2.5( & 3.8) \\
\hline Large-scale precip. $\left[\mathrm{mm} \mathrm{day}^{-1}\right]$ & $17.6(12.8 ; 21.4)$ & $19.8(14.5 ; 23.3)$ & $17.1(11.8 ; 20.8)$ \\
\hline $\mathrm{LWC}\left[\mathrm{mg} \mathrm{kg}^{-1}\right]$ & $29.4(16.1 ; 38.3)$ & $38.6(20.4 ; 50.9)$ & $37.5(20.4 ; 47.1)$ \\
\hline IWC $\left[\mathrm{mg} \mathrm{kg}^{-1}\right]$ & $5.4(4.1 ; 6.4)$ & $6.2(4.7 ; 7.6)$ & $6.6(5.2 ; 7.9)$ \\
\hline $\mathrm{CDNC}\left[\mathrm{cm}^{-3}\right]$ & $42.2(40.0 ; 42.7)$ & $50.5(40.8 ; 55.1)$ & $60.7(45.9 ; 81.6)$ \\
\hline $\mathrm{SO}_{2}\left[\mathrm{pg} \mathrm{kg}^{-1}\right]$ & $23.2(14.6 ; 27.7)$ & $36.9(19.9 ; 47.6)$ & $148.8(97.2 ; 173.7)$ \\
\hline $\mathrm{BC}\left[\mathrm{pg} \mathrm{kg}^{-1}\right]$ & $9.1(6.2 ; 10.9)$ & $11.9(7.2 ; 15.0)$ & $41.7(25.1 ; 53.1)$ \\
\hline
\end{tabular}
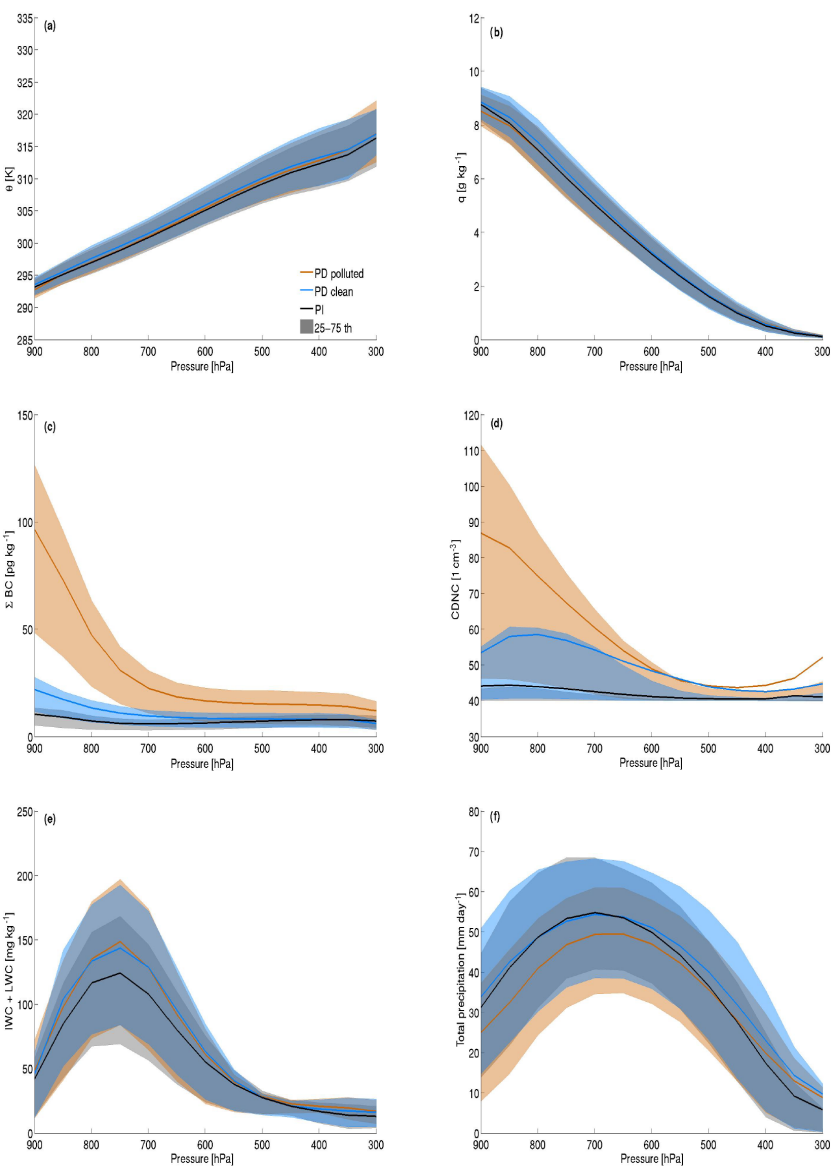

Figure 4. Means (solid lines) and 25-75th percentiles (shades) of PD polluted (orange), PD clean (blue) and PI (black) WCB trajectories as a function of pressure for potential temperature (a), specific humidity (b), black carbon mass mixing ratio (c), cloud droplet number concentration (d), total condensate (sum of LWC and IWC) (e) and total surface precipitation (f).

even more CCNs are available, precipitation is more strongly reduced. Thus, Fig. 5b nicely shows that for the same liquid and ice water content, less can be converted to precipitation shifting the phase curve in the PD polluted sample to the left.
An increase in liquid and ice water content due to a reduced precipitation formation can be observed when going from PI to PD clean conditions.

The slight delay in the precipitation formation between $\mathrm{PD}$ clean and PD polluted trajectories could cause a spatial shift in the location of precipitation if a WCB consisted entirely of clean or polluted trajectories. In order to investigate, how many trajectories of one WCB are polluted, we calculate, for every point in time when a WCB starts with more than 50 trajectories from the black box shown in Fig. 2, the fraction of all trajectories that are classified as polluted. The results are shown in Fig. 6. As an example, for the majority of points in time ( $\sim 145)$, only $0-5 \%$ of all trajectories belonging to one WCB are classified as polluted. Thus, it can be seen that for the majority of time steps in which WCB trajectories start, less than $20 \%$ of all starting trajectories are classified as "polluted". Given that very few strongly polluted WCBs exist, it is not surprising that hardly any differences are observed in the DJF mean precipitation between pre-industrial and present-day conditions in Fig. 2. In other words, the systematic effect of pollution observed in Fig. 5 is blurred by the high variability of inflow conditions for WCBs.

\section{Conclusions}

In this study we have analysed the possible impact of aerosol particles on precipitation formation in WCBs of winter time extratropical cyclones in the North Pacific using the ECHAM6 global climate model coupled to the aerosol module HAM. We chose the North Pacific because here the difference in aerosol burden and aerosol optical depth between present-day and pre-industrial times is among the largest due to the rise in emissions in south-eastern Asia. When combined with the prevailing westerly winds, if differences in aerosol load upwind of the genesis regions of extratropical cyclones have an effect on them, we expect to see an effect in this region.

To investigate in detail the possible impact of aerosols on precipitation, we selected the most polluted and cleanest trajectories occurring in the PD simulations. The polluted tra- 

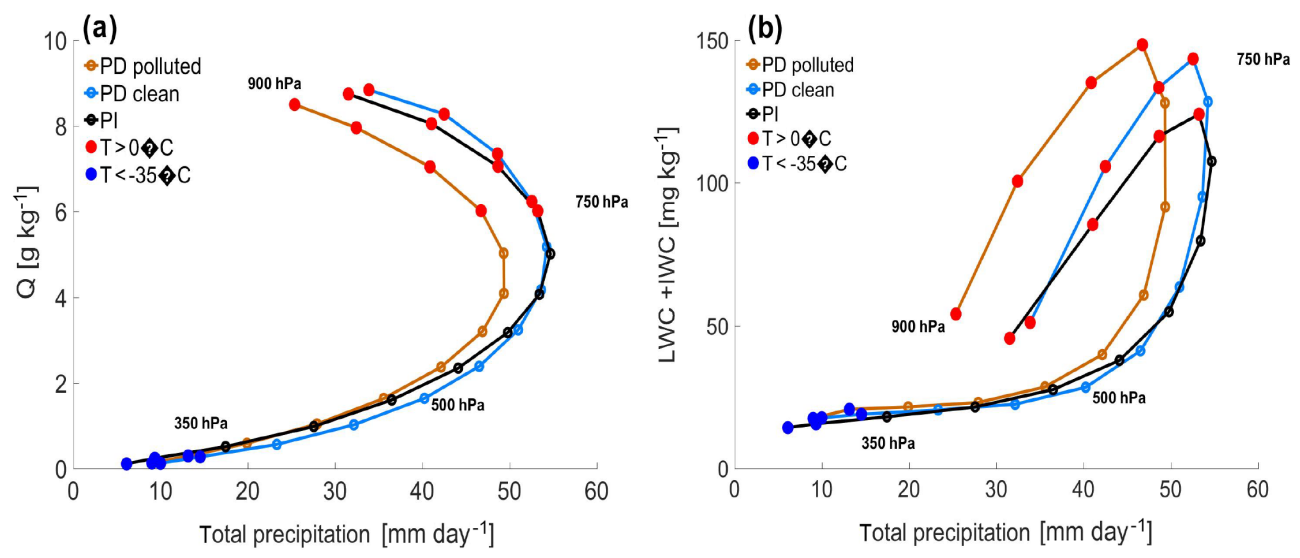

Figure 5. Phase diagram for the three categories of WCB trajectories: PD polluted (orange), PD clean (blue) and PI (black). (a) Mean specific humidity $(q)$ and (b) mean total condensate $(\mathrm{LWC}+\mathrm{IWC})$ as function of total precipitation; values are shown for $50 \mathrm{hPa}$ thick vertical layers, from 900 to $300 \mathrm{hPa}$. The 750 and $350 \mathrm{hPa}$ levels are marked and the red (blue) dots denote temperatures above $0{ }^{\circ} \mathrm{C}$ (below $-35^{\circ} \mathrm{C}$ ).

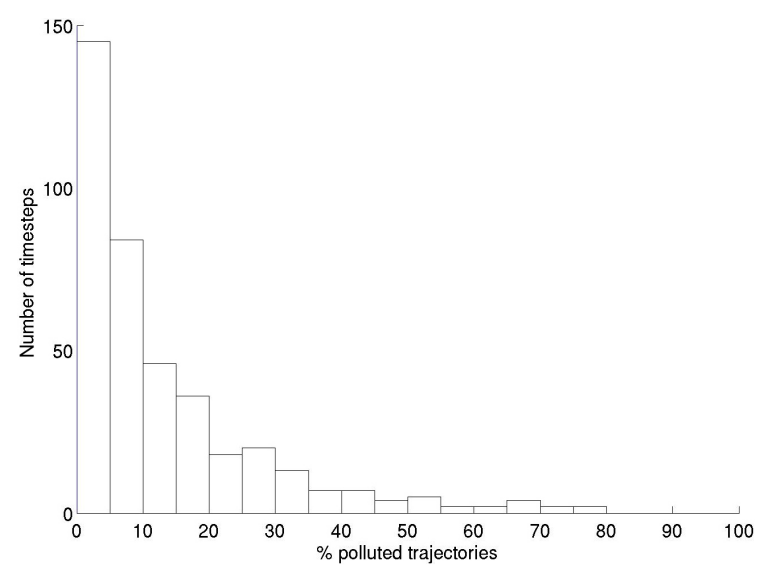

Figure 6. Histogram of the fraction of polluted WCB trajectories (in percent) as a function of the time steps obtained from all days on which more than $50 \mathrm{WCB}$ trajectories start in the black box.

jectories start with black carbon aerosol concentrations that are 5-10 times higher. The comparison between the most polluted and cleanest trajectories shows that for the most polluted cases, CDNC is clearly increased and the precipitation formation is reduced for a given total water content.

Our main findings are that despite these pronounced differences in the PD clean and PD polluted trajectories, the overall amount of precipitation in the North Pacific has hardly changed between pre-industrial and present-day conditions. As has been shown in Fig. 6, WCBs consist of a mixture of clean and polluted trajectories. Typically, there are many more clean trajectories in one WCB than polluted ones. This means that the effect of precipitation suppression in the most polluted WCB trajectories is damped by the more numerous clean trajectories. This combined with the large variability of total condensate and total precipitation in the different WCBs explains why no signal in precipitation can be detected in extratropical cyclones due to anthropogenic aerosol particles.

Our study confirms the findings by Igel et al. (2013) for a single warm front where no change in overall precipitation was found. A shift in precipitation as found by Thompson and Eidhammer (2014) is not inconsistent with our results because we showed that the amounts of precipitation are very variable within different WCB trajectories. The results shown in Wang et al. (2014a, b), however, show a clear impact of anthropogenic aerosols on the North Pacific storm track with an invigoration of winter cyclones and an associated increase in precipitation. Whereas the increase in LWP and CDNC in the mean fields can also be seen in our study, we use a very different method for the evaluation of the impact of aerosols on precipitation formation. In Wang et al. (2014a, b) the impact of anthropogenic aerosols is investigated by comparing simulations with different aerosol loadings. In our approach, we use a feature-based method in order to only investigate the impact on precipitation formation along the strongly ascending WCB trajectories. The Lagrangian approach with following the air parcels enables us to directly assess the impact of aerosols on the most cloudproducing airstream in extratropical cyclones in isolation, i.e. independently of other precipitating cloud systems. As shown in Pfahl et al. (2014), WCBs lead to $\sim 60 \%$ of the total precipitation in the North Pacific. Our results suggest that precipitation formation in the WCB trajectories is not strongly influenced by aerosols. However, we cannot make any statement about the precipitation formation in cloud systems which are not as strongly dynamically driven as a WCB. Therefore, our results are not necessarily contradictory to Wang et al. (2014a, b). Also the fact that we use another global climate model and that the microphysical parameterizations are a large source of uncertainty explains why the impact of aerosols on clouds and precipitation is not directly comparable and further research is needed. 
This study, however, has several caveats. First of all, it is a pure model study because no observational climatological data of the impact of aerosol particles on extratropical cyclones exist. Aerosol impacts on clouds and precipitation are generally hard to detect in observational studies because remote sensing studies suffer from not being able to detect aerosols and clouds simultaneously. Moreover, they present an Eulerian view whereas we analysed the possible impact of aerosols on WCBs in a Lagrangian way.

Another caveat is that WCBs are less well resolved in a global climate model than they are in the regional model studies cited above. Given that the regional model study by Igel et al. (2013) also did not find an effect on total precipitation, the resolution may not be a major issue. A more important shortcoming could be that we used climatological sea surface temperatures which, to a large extent, control the global mean evaporation and hence precipitation rates. Thus, changes in the overall amount of precipitation could be larger if we had coupled the atmospheric GCM to a mixed-layer ocean or a full dynamic ocean model.

Data availability. The ECHAM data for the North Pacific and the WCB trajectories are available upon request.

Competing interests. The authors declare that they have no conflict of interest.

Acknowledgements. E. Madonna and K. Witlox acknowledge support by the ETH Research Grant CH2-01 11-1.

Edited by: A. Ding

Reviewed by: two anonymous referees

\section{References}

Baeumer, D. and Vogel, B.: An unexpected pattern of distinct weekly periodicities in climatological variables in Germany, Geophys. Res. Lett., 34, L03819, doi:10.1029/2006g1028559, 2007.

Borys, R. D., Lowenthal, D. H., Cohn, S. A., and Brown, W. O. J.: Mountaintop and radar measurements of anthropogenic aerosol effects on snow growth and snowfall rate, Geophys. Res. Lett., 30, 1538, doi:10.1029/2002GL016855, 2003.

Boucher, O. and Quaas, J.: Water vapour affects both rain and aerosol optical depth, Nature Geosci., 6, 4-5, doi:10.1038/ngeo1692, 2013.

Boucher, O., Randall, D., Artaxo, P., Bretherton, C., Feingold, G., Forster, P., Kerminen, V.-M., Kondo, Y., Liao, H., Lohmann, U., Rasch, P., Satheesh, S. K., Sherwood, S., Stevens, B., and Zhang, X.-Y.: Clouds and Aerosols, in: Climate Change 2013: The Physical Science Basis. Contribution of Working Group I to the Fifth Assessment Report of the Intergovernmental Panel on Climate Change, edited by: Stocker, T., Qin, D., Plattner, G.-K., Tignor,
M., Allen, S. K., Boschung, J., Nauels, A., Xia, Y., Bex, V., and Midgley, P. M., 571-657, Cambridge Univ. Press, Cambridge, United Kingdom and New York, NY, USA, 2013.

Browning, K. A.: Conceptual models of precipitation systems, Weather Forecast., 1, 23-41, 1986.

Chen, S. J., Kuo, Y. H., Zhang, P. Z., and Bai, Q. F.: Synoptic climatology of cyclogenesis over east Asia, 1958-1987, Mon. Weather Rev., 119, 1407-1418, 1991.

Croft, B., Lohmann, U., Martin, R. V., Stier, P., Wurzler, S., Feichter, J., Hoose, C., Heikkilä, U., van Donkelaar, A., and Ferrachat, S.: Influences of in-cloud aerosol scavenging parameterizations on aerosol concentrations and wet deposition in ECHAM5-HAM, Atmos. Chem. Phys., 10, 1511-1543, doi:10.5194/acp-10-1511-2010, 2010.

Dee, D. P., Uppala, S. M., Simmons, A. J., Berrisford, P., Poli, P., Kobayashi, S., Andrae, U., Balmaseda, M. A., Balsamo, G., Bauer, P., Bechtold, P., Beljaars, A. C. M., van de Berg, L., Bidlot, J., Bormann, N., Delsol, C., Dragani, R., Fuentes, M., Geer, A. J., Haimberger, L., Healy, S. B., Hersbach, H., Holm, E. V., Isaksen, L., Kallberg, P., Koehler, M., Matricardi, M., McNally, A. P., Monge-Sanz, B. M., Morcrette, J. J., Park, B. K., Peubey, C., de Rosnay, P., Tavolato, C., Thepaut, J. N., and Vitart, F.: The ERA-Interim reanalysis: configuration and performance of the data assimilation system, Q. J. Roy. Meteor. Soc., 137, 553-597, doi:10.1002/qj.828, 2011.

Denman, K., Brasseur, G., Chidthaisong, A., Ciais, P., Cox, P., Dickinson, R., Hauglustaine, D., Heinze, C., Holland, E., Jacob, D., Lohmann, U., Ramachandran, S., Silva Dias, P., Wofsy, S., and Zhang, X.: Couplings between changes in the climate system and biogeochemistry, in: Climate Change 2007: The Physical Science Basis. Contribution of Working Group I to the Fourth Assessment Report of the Intergovernmental Panel on Climate Change, edited by: Solomon, S., Qin, D., Manning, M., Chen, Z., Marquis, M., Averyt, K. B., Tignor, M., and Miller, H. L., 499-588, Cambridge Univ. Press, Cambridge, United Kingdom and New York, NY, USA, 2007.

Ding, A., Wang, T., Xue, L., Gao, J., Stohl, A., Lei, H., Jin, D., Ren, Y., Wang, X., Wei, X., Qi, Y., Liu, J., and Zhang, X.: Transport of north China air pollution by mid-latitude cyclones: Case study of aircraft measurements in summer 2007, J. Geophys. Res., 114, D08304, doi:10.1029/2008JD011023, 2009.

Eckhardt, S., Stohl, A., Wernli, H., James, P., Forster, C., and Spichtinger, N.: A 15-Year Climatology of Warm Conveyor Belts, J. Climate, 17, 218-237, 2004.

Granier, C., Bessagnet, B., Bond, T., D’Angiola, A., Denier van der Gon, H., Frost, G. J., Heil, A., Kaiser, J. W., Kinne, S., Klimont, Z., Kloster, S., Lamarque, J.-F., Liousse, C., Masui, T., Meleux, F., Mieville, A., Ohara, T., Raut, J.-C., Riahi, K., Schultz, M. G., Smith, S. J., Thompson, A., Aardenne, J., Werf, G. R., and Vuuren, D. P.: Evolution of anthropogenic and biomass burning emissions of air pollutants at global and regional scales during the 1980-2010 period, Climatic Change, 109, 163-190, doi:10.1007/s10584-011-0154-1, 2011.

Hoose, C., Lohmann, U., Erdin, R., and Tegen, I.: Global influence of dust mineralogical composition on heterogeneous ice nucleation in mixed-phase clouds, Environ. Res. Lett., 3, 025003, doi:10.1088/1748-9326/3/2/025003, 2008.

Igel, A. L., van den Heever, S. C., Naud, C. M., Saleeby, S. M., and Posselt, D. J.: Sensitivity of warm-frontal processes to cloud- 
nucleating aerosol concentrations, J. Atmos. Sci., 70, 17681783, doi:10.1175/JAS-D-12-0170.1, 2013.

Joos, H. and Wernli, H.: Influence of microphysical processes on the potential vorticity development in a warm conveyor belt: a casestudy with the limited-area model COSMO, Q. J. Roy. Meteor. Soc., 138, 407-418, 2012.

Jung, T., Gulev, S. K., Rudeva, I., and Soloviov, V.: Sensitivity of extratropical cyclone characteristics to horizontal resolution in the ECMWF model., Q. J. Roy. Meteor. Soc., 132, 1839-1857, doi:10.1256/qj.05.212, 2006.

Klimont, Z., Smith, S. J., and Cofala, J.: The last decade of global anthropogenic sulfur dioxide: 2000-2011 emissions, Environ. Res. Lett., 8, 014003, doi:10.1088/1748-9326/8/1/014003, 2013.

Lamarque, J.-F., Bond, T. C., Eyring, V., Granier, C., Heil, A., Klimont, Z., Lee, D., Liousse, C., Mieville, A., Owen, B., Schultz, M. G., Shindell, D., Smith, S. J., Stehfest, E., Van Aardenne, J., Cooper, O. R., Kainuma, M., Mahowald, N., McConnell, J. R., Naik, V., Riahi, K., and van Vuuren, D. P.: Historical (1850-2000) gridded anthropogenic and biomass burning emissions of reactive gases and aerosols: methodology and application, Atmos. Chem. Phys., 10, 7017-7039, doi:10.5194/acp10-7017-2010, 2010.

Levin, Z. and Cotton, W. R. (Eds.): Aerosol Pollution Impact on Precipitation: A Scientific Review, Springer Science \& Business Media, 386 pp., ISBN-13: 978-1-4020-8689-2, 2008a.

Levin, Z. and Cotton, W. R. (Eds.): Aerosol Pollution Impact on Precipitation: A Scientific Review, chap. Effects of pollution and biomass aerosols on clouds and precipitation: observational studies, 205-241, Springer, 2008b.

Lin, H. and Leaitch, W. R.: Development of an in-cloud aerosol activation parameterization for climate modelling, in: Proceedings of the WMO Workshop on Measurement of Cloud Properties for Forecasts of Weather, Air Quality and Climate, 328-335, World Meteorol. Organ., Geneva, 1997.

Lohmann, U. and Hoose, C.: Sensitivity studies of different aerosol indirect effects in mixed-phase clouds, Atmos. Chem. Phys., 9, 8917-8934, doi:10.5194/acp-9-8917-2009, 2009.

Lohmann, U., Spichtinger, P., Jess, S., Peter, T., and Smit, H.: Cirrus cloud formation and ice supersaturated regions in a global climate model, Environ. Res. Lett., 3, 045022, doi:10.1088/17489326/3/4/045022, 2008.

Lohmann, U., Lüönd, F., and Mahrt, F.: An introduction to clouds: From the microscale to climate, Cambridge University Press, 2016.

Madonna, E., Wernli, H., Joos, H., and Martius, O.: Warm conveyor belts in the ERA-Interim dataset (1979-2010). Part I: Climatology and potential vorticity evolution, J. Climate, 27, 3-26, doi:10.1175/jcli-d-12-00720.1, 2014.

Martinez-Alvarado, O., Joos, H., Chagnon, J., Boettcher, M., Gray, S., Plant, R., Methven, J., and Wernli, H.: The dichotomous structure of the warm conveyor belt, Q. J. Roy. Meteor. Soc., 140, 1809-1824, doi:10.1002/qj.2276, 2014.

Neubauer, D., Lohmann, U., Hoose, C., and Frontoso, M. G.: Impact of the representation of marine stratocumulus clouds on the anthropogenic aerosol effect, Atmos. Chem. Phys., 14, 1199712022, doi:10.5194/acp-14-11997-2014, 2014.

Nordeng, T. E.: Extended versions of the convective parameterization scheme at ECMWF and their impact on the mean and tran- sient activity of the model in the tropics, Tech. Rep. 206, European Centre for Medium-Range Weather Forecasts, 1994.

Pfahl, S., Madonna, E., Boettcher, M., Joos, H., and Wernli, H.: Warm Conveyor Belts in the ERA-Interim Dataset (1979-2010). Part II: Moisture Origin and Relevance for Precipitation, J. Climate, 27, 27-40, doi:10.1175/JCLI-D-13-00223.1, 2014.

Reutter, P., Trentmann, J., Seifert, A., Neis, P., Su, H., Chang, D., Herzog, M., Wernli, H., Andreae, M. O., and Pöschl, U.: 3$\mathrm{D}$ model simulations of dynamical and microphysical interactions in pyroconvective clouds under idealized conditions, Atmos. Chem. Phys., 14, 7573-7583, doi:10.5194/acp-14-75732014, 2014.

Rosenfeld, D. and Bell, T. L.: Why do tornados and hailstorms rest on weekends?, J. Geophys. Res., 116, D20211, doi:10.1029/2011jd016214, 2011.

Rosenfeld, D., Lohmann, U., Raga, G. B., O’Dowd, C. D., Kulmala, M., Fuzzi, S., Reissell, A., and Andreae, M. O.: Flood or drought: How do aerosols affect precipitation?, Science, 321, 1309-1313, 2008.

Sanchez-Lorenzo, A., Laux, P., Hendricks Franssen, H.-J., Calbó, J., Vogl, S., Georgoulias, A. K., and Quaas, J.: Assessing largescale weekly cycles in meteorological variables: a review, Atmos. Chem. Phys., 12, 5755-5771, doi:10.5194/acp-12-57552012, 2012.

Seinfeld, J. H. and Pandis, S. N.: Atmospheric chemistry and physics: From air pollution to climate change, Wiley, Hoboken, New Jersey, 1998.

Stevens, B., Giorgetta, M., Esch, M., Mauritsen, T., Crueger, T., Rast, S., Salzmann, M., Schmidt, H., Bader, J., Block, K., Brokopf, R., Fast, I., Kinne, S., Kornblueh, L., Lohmann, U., Pincus, R., Reichler, T., and Roeckner, E.: Atmospheric component of the MPI-M Earth System Model: ECHAM6, J. Adv. Modeling Earth Systems, 5, 146-172, 2013.

Stohl, A.: A 1-year Lagrangian "climatology" of airstreams in the Northern Hemisphere troposphere and lowermost stratosphere, J. Geophys. Res., 106, 7263-7279, 2001.

Sundqvist, H., Berge, E., and Kristjánsson, J. E.: Condensation and Cloud Parameterization Studies with a Mesoscale Numerical Weather Prediction Model, Mon. Weather Rev., 117, 1641-1657, 1989.

Thompson, G. and Eidhammer, T.: A study of aerosol impacts on clouds and precipitation development in a large winter cyclone, J. Atmos. Sci., 71, 3636-3658, doi:10.1175/JAS-D-13-0305.1, 2014.

Tiedtke, M.: A comprehensive mass flux scheme for cumulus parameterization in large-scale models, Mon. Weather Rev., 117, 3040-3061, 1989.

Wang, Y., Wang, M., Zhang, R., Ghan, S. J., Lin, Y., Hu, J., Pan, B., Levy, M., Jiang, J. H., and Molina, M. J.: Assessing the effects of anthropogenic aerosols on Pacific storm track using a multiscale global climate model, P. Natl. Acad. Sci. USA, 111, 6894-6899, 2014a.

Wang, Y., Zhang, R., and Saravanan, R.: Asian pollution climatically modulates mid-latitude cyclones following hierarchical modelling and observational analysis, Nature comm., 5, 3098, doi:10.1038/ncomms4098, 2014b.

Wernli, H. and Davies, H. C.: A Lagrangian-based analysis of extratropical cyclones. I: The method and some applications, Q. 
J. Roy. Meteor. Soc., 123, 467-489, doi:10.1256/smsqj.53810, 1997.

Wernli, H. and Schwierz, C.: Surface cyclones in the ERA-40 dataset (1958-2001). Part I: Novel identification method and global climatology, J. Atmos. Sci., 63, 2486-2507, 2006.

Yan, H., Qian, Y., Zhao, C., Wang, H., Wang, M., Yang, B., Liu, Y., and $\mathrm{Fu}, \mathrm{Q}$.: A new approach to modeling aerosol effects on East Asian climate: Parametric uncertainties associated with emissions, cloud microphysics and their interactiosn, J. Geophys. Res., 120, 8905-8924, 2015.

Yuter, S. E., Miller, M. A., Parker, M. D., Markowski, P. M., Richardson, Y., Brooks, H., and Straka, J. M.: Comment on "Why do tornados and hailstorms rest on weekends?" by D. Rosenfeld and T. Bell, J. Geophys. Res., 118, 7332-7338, doi:10.1002/jgrd.50526, 2013.
Zhang, K., O’Donnell, D., Kazil, J., Stier, P., Kinne, S., Lohmann, U., Ferrachat, S., Croft, B., Quaas, J., Wan, H., Rast, S., and Feichter, J.: The global aerosol-climate model ECHAM-HAM, version 2: sensitivity to improvements in process representations, Atmos. Chem. Phys., 12, 8911-8949, doi:10.5194/acp-12-89112012, 2012.

Zhang, R. Y., Li, G. H., Fan, J. W., Wu, D. L., and Molina, M. J.: Intensification of pacific storm track linked to asian pollution, $\mathrm{P}$. Natl. Acad. Sci. USA, 104, 5295-5299, 2007.

Zhou, R. and Deng, Y.: A model analysis of the interactions between East Asian anthropogenic aerosols and North Pacific atmospheric transientsboreal winter, J. Geophys. Res., 118, 306-316, 2013. 